\title{
Research
}

\section{Effect of weather on GP home visits:}

\author{
a cross-sectional study
}

\begin{abstract}
\section{Background}

GPs in the UK conduct $>13$ million home visits each year. The visits, which are resource intensive, are usually to the frailest patients who are least resilient to adverse weather.

\section{Aim}

To explore the relationship between meteorological variables (temperature, rainfall, sunshine) and temporal variables (day of the week, season) with GP home visits (HVs).

\section{Design and setting}

A cross-sectional study using data provided by Herts Urgent Care for its GP acute in-hours visiting service and UK Meteorological (Met) Office weather data for the Herts \& South East region of the UK
\end{abstract}

\section{Method}

The association between the number of GP $\mathrm{HVs}$ and weather and temporal variables was explored using univariable and multivariable negative binomial regression.

\section{Results}

There was a significant $0.4 \%$ decrease in $\mathrm{HVs}$ per degrees Celsius increase in minimum temperature (incidence rate ratio [IRR] 0.996 , $95 \%$ confidence interval $[\mathrm{Cl}]=0.993$ to 0.999 ], and a $0.4 \%$ decrease per hour increase in sunshine (IRR 0.996, 95\% Cl $=0.992$ to 1.000 ) as well as significant decreases in weekday HVs compared with Mondays (Thursday IRR 0.824 , $95 \% \mathrm{Cl}=0.790$ to 0.859 ). There were $6.2 \%$ fewer $\mathrm{HVs}$ in summer compared with winter (IRR $0.938,95 \% \mathrm{Cl}=0.902$ to 0.975 ). Multivariable negative binomial regression showed nonsignificant relationships between meteorological variables and $\mathrm{HV}$ s, but a significant day-of-theweek relationship.

\section{Conclusion}

GP HVs increased on cold days and fell on sunnier days. The effect sizes were small so it is unlikely that there is any clinically significant effect of weather on HVs in this acute GP visit setting. A tentative conclusion might also be that GPs in this system can deliver care to frail housebound patients in most weather conditions.

\section{Keywords}

consultation; general practice; Hertfordshire; home visits; meteorology; weather

\section{INTRODUCTION}

Treating patients at their own home has always been part of a UK NHS GP's workload. As home visits are estimated to represent $>13$ million consultations throughout the UK each year, any associations with weather patterns might have implications for GPs' workload and, due to the volume of care delivered by primary care $(90 \%$ of NHS activity), any small effect may have an amplified impact on the wider NHS, such as A\&E attendance and ambulance usage.

GPs are under increasing pressure with regards to their workload. Between 1998 and 2014 there was a 24\% increase in GP consultations lincluding an increase of 40 million since 2008), with 340 million annual consultations delivered by a primary care workforce of 42000 .

GP home visits are a fundamental aspect of UK primary care and are usually reserved for those who are housebound, permanently or temporarily through illness. These are more likely to be those who are frail and older, who are less mobile, and who may experience difficulties accessing GP services during adverse weather, such as when it is very cold or wet. Ensuring delivery of effective community-based care to this group is often cited as key to models of long-term sustainability of the health service.?

Home visits accounted for around 2-4\% of the 340 million annual GP consultations conducted in 2014, ${ }^{3}$ and are the most time-consuming type of consultation. On

0 Oyawoye, BSc, medical student; L Marston MSc, PhD, principal research associate; M Jones, MSc, MD, FRCGP. FAcadMEd, clinical associate professor, University College London Medical School, London.

\section{Address for correspondence}

Melvyn Jones, Department of Primary Care and Population Health, University College London Medical School (Royal Free Campus), Rowland Hill Street, London NW3 2PF, UK. average, they take 23.4 minutes versus 11.7 for surgery consultations (2006/7 data). ${ }^{4} \mathrm{GP}$ visit rates have decreased steadily by about $2 \%$ per year. ${ }^{5}$ At the same time, more older patients are living in the community.

Winter pressures present a major challenge for the NHS, with an increased burden of respiratory infections in primary care ${ }^{6}$ increased proportions of older people attending $A \& E$, a reduced ability of social services to provide care to the vulnerable during adverse weather, ${ }^{7}$ and increased proportions of patients needing to be admitted to hospital. ${ }^{8}$ Part of winter pressures is the effect of flu, with the older frail more susceptible to influenza-like illness, and its more serious consequences, which peaks in winter months. ${ }^{9}$

Cold temperatures in the UK have been shown to have an impact on population mortality, ${ }^{10}$ but are thought to have little direct temporal relationship with primary care consultation rates. ${ }^{11}$ There is, however, a strong association with temperature levels 15 days previously, suggesting a relationship with cold weather and infection. ${ }^{11}$ This delayed effect of cold weather has also been seen in warmer countries, such as Greece. ${ }^{12}$ Conversely, the Greek study found a positive correlation between relative humidity and the proportion of house call visits for respiratory infections. More widely in primary care, a relationship has been demonstrated (in Birmingham, UK) between extreme weather - both hot and cold - and increased ambulance call-out and response

Email: melvyn.jonesवucl.ac.uk

Submitted: 24 August 2018; Editor's response: 9 October 2018; final acceptance: 2 November 2018.

CBritish Journal of General Practice

This is the full-length article (published online 9 Apr 2019) of an abridged version published in print. Cite this version as: Br J Gen Pract 2019; DOI: https://doi.org/10.3399/bjgp19X702257 


\section{How this fits in}

Winter pressures on the NHS Iparticularly on A\&E services) have been studied extensively in the UK. Previous research has found an association between cold weather and respiratory infections in primary care, and the number of ambulance call-outs and weather. This paper examines links between weather throughout the year and the provision of acute GP home visits, and suggests this is a robust model that appears to deliver a key NHS service in most weather conditions.

times..$^{13}$ Internationally, adverse weather affects emergency ambulance service calls in Hong Kong. 14 Weather factors predict the demand for emergency ambulance services by older people, people with more severe conditions, and those from lower social economic groups. ${ }^{14}$

Other research has looked at the impact of the weather on people with specific health conditions such as asthma. ${ }^{15}$ Studies looking at the association between thunderstorms in 1994 and acute asthma found that epidemics of acute asthma consultations related temporally and spatially to thunderstorms throughout England, Scotland, and Wales. 16,17

There is evidence of an impact of weather on specific groups and those with specific health conditions impacting on UK GP services, and international research that suggests a broader impact of adverse weather on primary care/emergency services, but there is no research exploring whether adverse weather impacts on GP home visiting, a key element of NHS service resilience.

\section{METHOD}

This is an exploratory study using a crosssectional analysis comparing the absolute numbers of GP visits delivered by an acute GP visiting service and weather data provided by the UK Meteorological (Met) Office.

\section{Setting}

Hertfordshire is a UK county on the outskirts of London, and is home to $>1$ million residents. The out-of-hours $(\mathrm{OOH})$ provision for Hertfordshire is provided by Herts Urgent Care (HUC). It also provides a unique service that offers land systematically records) GP home visits for new and acute problems for this population. The service is called the acute in-hours visiting service (AlHVS). Within the service, calls are triaged against eligibility criteria, before details la clinical summary and the clinical problem from the patient's GP) are passed to a GP in a HUC car with a driver. The service does not cover all home visits for pre-planned or ongoing issues, for example, palliative care. Practices can elect not to use the service, and there is a cap on workload lusually two visits per practice per dayl, which may be reduced if HUC has staffing issues. Home visits are conducted on weekdays only from $8.00 \mathrm{am}$ to $6.30 \mathrm{pm}$. The $\mathrm{OOH}$ service operates separately, and the $\mathrm{OOH}$ data are not included in this study.

\section{Weather data}

Weather data were obtained with permission from the UK Met Office. The data related to that available from two weather stations, Rothamsted and Heathrow. Rothamsted is within the Hertfordshire region. The weather variables that were taken from this station were:

- daily minimum temperature $\left({ }^{\circ} \mathrm{C}\right)$;

- daily total rainfall (mm), and

- number of hours with relative humidity $\geq 90 \%$.

Heathrow weather station gathers comprehensive weather data and was used to collect information on hours of sunshine. This weather station is the closest that could provide this data and is located around 40 miles $(64 \mathrm{~km})$ south of Hertfordshire.

Minimum temperature was divided into two groups, cold and not cold, for analysis, with $4^{\circ} \mathrm{C}$ the cut-off between the two groups based on changes in physical activity in older patients. ${ }^{18}$ The data were also combined to compare home visits on days with rain versus no rain. For rainfall, no rain was defined as the number of millimetres of rain being zero. Conversely, days with rain were defined as days with any rain.

\section{Statistical analysis}

Statistical analysis was performed using IBM SPSS Statistics software (version 24) and Stata (version 14). Negative binomial regression was used to investigate associations between weather conditions, temporal factors (season [based on the equinoxes] and days of the week), and home visits. Univariable analysis of each weather and temporal variable was carried out, and then a multivariable analysis was performed.

\section{RESULTS}

In all, $>2$ years of data were retrieved (from 2 February 2015 to 31 March 2017), with 


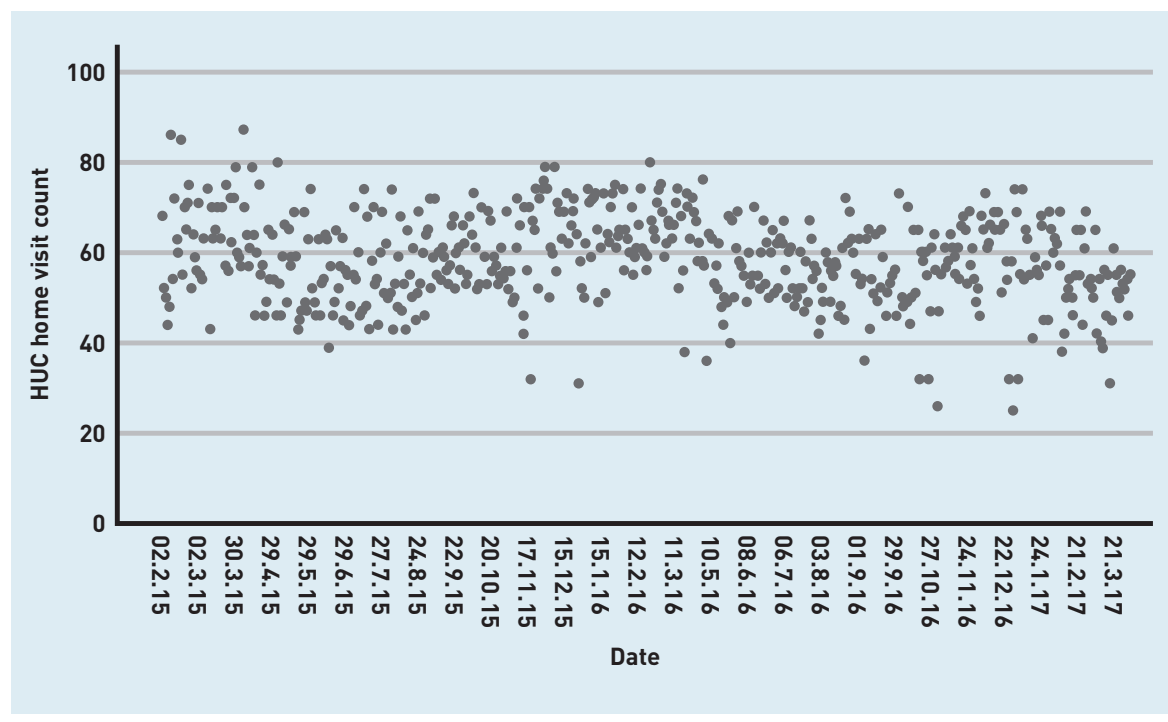

Figure 1. Herts Urgent Care GP visits by date.

HUC = Herts Urgent Care.

Figure 2. Daily home visits by minimum temperature.

HUC $=$ Herts Urgent Care.

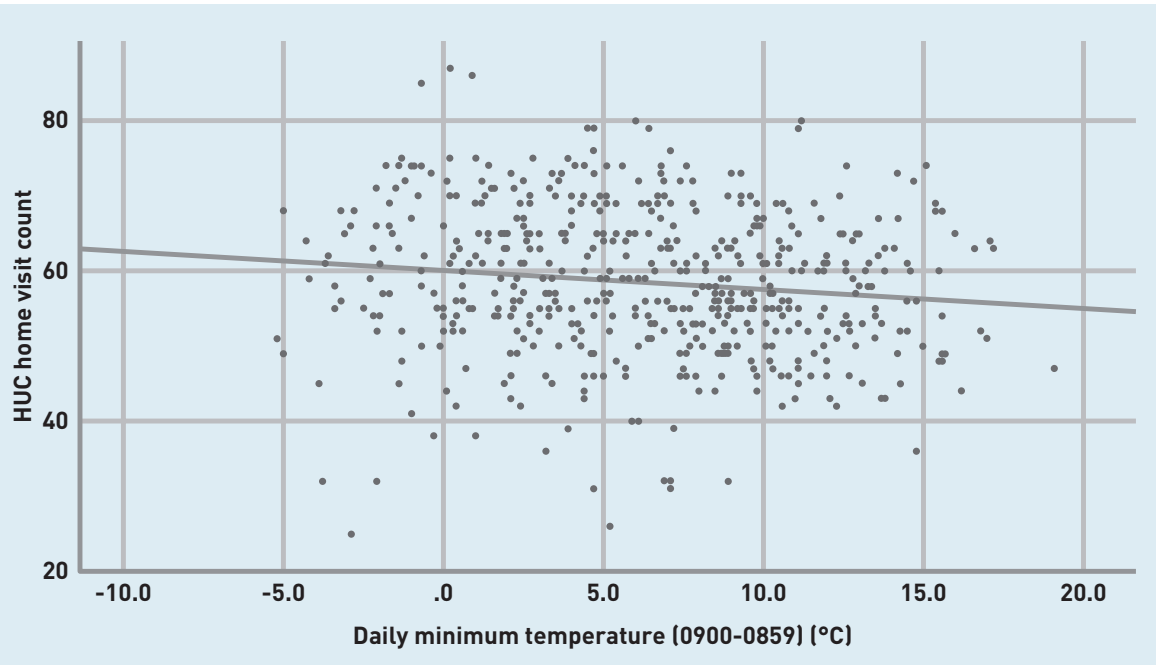

\section{Cold versus not cold}

In the univariable analysis, there was a 4.3\% increase (IRR $1.043,95 \% \mathrm{Cl}=1.013$ to 1.075 ) in the likelihood of a home visit when it was cold, compared with when it was not cold.

\section{Home visits and number of hours of sunshine}

There was a statistically significant $0.4 \%$ decrease (IRR 0.996, 95\% Cl=0.992 to 1.000) in the likelihood of a home visit for every 1 hour increase in total sunshine.

\section{Home visits and rainfall}

There was a non-significant $0.1 \%$ increase (IRR $1.001,95 \% \mathrm{Cl}=0.997$ to 1.004 ) in the likelihood of a home visit for each $\mathrm{mm}$ increase of rainfall per day (Table 1).

The authors found a non-significant $1.5 \%$ increase in the likelihood of a home visit when it rained compared to when it did not (IRR $1.015,95 \% \mathrm{Cl}=0.986$ to 1.044 ) (Table 1).

\section{Home visits and number of hours with relative humidity $\geq 90 \%$}

There was a non-significant $0.2 \%$ increase (IRR 1.002, $95 \% \mathrm{Cl}=1.000$ to 1.004 ) in the likelihood of a home visit for every 1-hour increase in duration of high relative humidity (Table 1).

\section{Home visits and temporal variables}

There was a significant day-of-the-week effect, with an 18\% decrease (IRR 0.824, $95 \% \mathrm{Cl}=0.790$ to 0.859 ) in the likelihood of a home visit on a Thursday compared with a Monday. Similar findings were shown for Tuesday, Wednesday, and Friday. There was a significant decrease (6.2\%) in the likelihood of home visits in summer compared with winter (IRR 0.938, 95\% $\mathrm{Cl}=0.902$ to 0.975 ) (Table 1).

\section{Multivariable analysis}

The multivariable model including all meteorological variables as continuous and temporal variables showed that there was no statistically significant effect on the number of GP home visits conducted when compared with all of the available weather variables. Minimum temperature, daily total sunshine, daily total rainfall, and relative humidity showed no significant effect. However, there was a strong day-of-theweek effect, with Tuesday to Friday showing a lower likelihood of a home visit compared with Monday. There was no significant effect of season (Table 2).

A multivariable analysis with cold versus not-cold variables instead of a continuous measure of temperature (Table 3) produced a non-significant $2.5 \%$ increase in the 


\section{Table 1. Univariate association between home visits and weather and temporal variables}

\begin{tabular}{lcc} 
Weather variable & IRR & $\mathbf{9 5 \%} \mathbf{C l}$ \\
\hline Minimum temperature, ${ }^{\circ} \mathrm{C}$ & 0.996 & 0.993 to 0.999 \\
\hline Cold/not cold & 1.043 & 1.013 to 1.075 \\
\hline Daily total sunshine, hours & 0.996 & 0.992 to 1.000 \\
\hline Total rainfall, mm & 1.001 & 0.997 to 1.004 \\
\hline Any rainfall & 1.015 & 0.986 to 1.044 \\
\hline Hours with humidity $>90 \%$ & 1.002 & 1.000 to 1.004 \\
\hline Monday & Reference & \\
\hline Tuesday & 0.855 & 0.820 to 0.891 \\
\hline Wednesday & 0.873 & 0.838 to 0.910 \\
\hline Thursday & 0.824 & 0.790 to 0.859 \\
\hline Friday & 0.867 & 0.832 to 0.904 \\
\hline Winter & Reference & \\
\hline Spring & 0.971 & 0.933 to 1.011 \\
\hline Summer & 0.938 & 0.902 to 0.975 \\
\hline Autumn & 0.986 & 0.949 to 1.025
\end{tabular}

$\mathrm{Cl}=$ confidence interval. IRR = incidence rate ratio.

likelihood of a home visit on cold days (IRR $1.025,95 \% \mathrm{Cl}=0.990$ to 1.061 ). The day-ofthe-week effect persisted.

\section{DISCUSSION}

\section{Summary}

There were weak but significant univariate associations between the daily home visit rates and daily minimum temperatures, as well as daily number of hours of sunshine. This was an inverse relationship with poorer

\section{Table 2. Multivariable analysis of weather and temporal variables} against HUC home visits

\begin{tabular}{lcc} 
Weather variable & IRR & 95\% Cl \\
\hline Minimum temperature, ${ }^{\circ} \mathrm{C}$ & 0.998 & 0.994 to 1.002 \\
\hline Daily total sunshine, hours & 0.998 & 0.994 to 1.002 \\
\hline Daily total rainfall, mm & 1.001 & 0.998 to 1.005 \\
\hline Hours with humidity $>90 \%$ & 1.000 & 0.998 to 1.002 \\
\hline Monday & Reference & \\
\hline Tuesday & 0.856 & 0.822 to 0.892 \\
\hline Wednesday & 0.874 & 0.839 to 0.910 \\
\hline Thursday & 0.824 & 0.791 to 0.859 \\
\hline Friday & 0.867 & 0.832 to 0.904 \\
\hline Winter & Reference & \\
\hline Spring & 0.988 & 0.946 to 1.032 \\
\hline Summer & 0.959 & 0.907 to 1.014 \\
\hline Autumn & 0.993 & 0.954 to 1.034 \\
\hline
\end{tabular}

$\mathrm{Cl}=$ confidence interval. $\mathrm{HUC}=$ Herts Urgent Care. $I R R=$ incidence rate ratio weather, that is, the colder and less sunny it was, the higher the GP home visiting rate was. Grouping the temperatures into cold versus not cold gave only a slightly stronger association, whereas a rain versus no rain analysis showed no significant association. In the multivariable analysis, these associations disappeared. Since these are non-significant small increases or decreases in activity, it is unlikely that the meteorological variables have any clinically meaningful effects. The day-of-the-week effect was already known and factored into service capacity, as is the winter effect and the NHS response to these winter pressures. $^{8}$

The numbers of home visits delivered is likely to be a complex relationship between service supply and patient demand. On the demand side, the factors that might influence activity include perceived and actual healthcare need by a patient lor their carer) and a perception by the patient that they are housebound. This perception of being housebound is likely to be sensitive to environmental conditions, so, for example, if a person is frail and has a high fever they may feel less able to attend a GP's surgery if it is very cold outside. On the supply side, home visit activity will be determined by the GP's perception of clinical need for a face-to-face consultation, based on the symptom or condition described, previous knowledge of the patient, and the ability to provide that service balanced against other clinical demands. The AlHVS model will add some complexity to this interaction in that the patient's eligibility criteria must also be met and HUC must have enough doctors/drivers available to provide the visit, which may again be weather dependent. Bad weather is also likely to impact on the efficiency of the service, as it will take longer to reach each individual, reducing service capacity. In view of this presumed non-linear relationship between supply and demand, it was unlikely that the authors would see a strong relationship between weather conditions and GP visits delivered.

\section{Strengths and limitations}

These acute GP home visits are coordinated by one central organisation, HUC, so obtaining the data for analysis was a simpler task than from multiple GP practices. GP home visit data are usually poorly recorded, as GPs are remote from IT systems: ${ }^{19}$ HUC data are used by commissioners to monitor the service, and thus are likely to be more reliably coded. Use of HUC data allows for a geographically defined population, where weather conditions experienced by patients 


\section{Table 3. Multivariable analysis of weather and temporal variables against HUC home visits (cold versus not cold)}

\begin{tabular}{lcc} 
Variables & IRR & $\mathbf{9 5 \%} \mathbf{C l}$ \\
\hline Cold & 1.025 & 0.990 to 1.061 \\
\hline Daily total sunshine, hours & 0.998 & 0.994 to 1.002 \\
\hline Daily total rainfall, mm & 1.001 & 0.998 to 1.005 \\
\hline Hours with humidity $\geq 90 \%$ & 1.000 & 0.998 to 1.002 \\
\hline Monday & Reference & \\
\hline Tuesday & 0.856 & 0.822 to 0.892 \\
\hline Wednesday & 0.873 & 0.837 to 0.909 \\
\hline Thursday & 0.824 & 0.791 to 0.859 \\
\hline Friday & 0.867 & 0.832 to 0.904 \\
\hline Winter & Reference & \\
\hline Spring & 0.991 & 0.950 to 1.034 \\
\hline Summer & 0.958 & 0.915 to 1.003 \\
\hline Autumn & 0.998 & 0.958 to 1.039
\end{tabular}

$\mathrm{Cl}=$ confidence interval. $\mathrm{HUC}=$ Herts Urgent Care. IRR $=$ incidence rate ratio. delivered on weekdays, so the authors lose 2/7 of their combined study home visit and weather data points. It is also possible that adverse weather and seasonal illness may impact on the availability of GPs and drivers in the same way as it does on patients, that is, adverse weather may impact on service delivery. The way in which HUC triages requests for home visits is complex. Though most requests will be accepted, some are signposted to other services, such as district nurses. It is unclear whether this is more likely to happen during adverse weather. Some visits may be deferred by practices late in the day, so the request may not always be linked temporally to the weather conditions.

There are also variations in visiting rate transferred by practices to AlHVS, so a practice effect may be apparent, and practices are periodically allowed to refer more during periods of stress, such as doctor sickness, which will not be weather linked.

This type of study is vulnerable to the 'ecological fallacy'; not every area in Hertfordshire, covered by HUC, will experience the same weather pattern. The Heathrow weather station is located around 40 miles south of Hertfordshire. Therefore, between these two areas there is room for local weather variability. This problem may apply more to rainfall, which is highly locally variable, but it is less likely to be an issue with temperature and hours of sunshine Imeasured by the more distant weather station). Weather is also not uniform during a day, so a short heavy rain storm may have less impact on behaviour than all-day driving rain, and rain at night should have no impact. However, the authors' visit data will only link data broadly to the weather data for the corresponding 24 hours. Similarly, longer periods of bad weather may influence activity patterns, with people being able to defer visit requests for a few days.

\section{Comparison with existing literature}

The authors were unable to find comparable studies looking at GP home visiting for unselected conditions and weather. There are little data on how primary care activity is related to weather beyond occasional reports, as a cause of missed GP appointments. ${ }^{20}$

\section{Implications for research and practice}

The results of the analysis largely point to no clinically important association between the meteorological variables and rate of GP home visits. The need for extra capacity on 
Mondays and in winter is already known to these services, but there is only one poo of GPs; if extra cover is being provided in winter there is presumably less clinical cover elsewhere (such as within 'normal general practices'). Although there are some statistically significant univariate associations, the effect sizes are small and disappear in the multivariable analysis. The possible good news is that this might be a resilient service that is able to deliver a GP home visiting service to the most vulnerable, in most weather conditions.

The occurrence of a delayed effect seen in other studies needs examination to determine, particularly for colder temperatures, whether there is a more significant association with lags from 1-20 days in temperature. The association with influenza could be examined. Influenza rates are highly seasonal and can have an effect on the number of home visits, especially with frail elderly patients. There could potentially be an opportunity to use more meteorological variables, and even more extreme weather circumstances, for example, snow, ice, hail, storms, floods, and so on. These more extreme weather events are rare in Hertfordshire, and would only generate one or two data points, so they may not be amenable to this type of analysis.

\section{Funding \\ None.}

\section{Ethical approval}

This study was approved by NHS Health Research Authority (IRAS Project ID: 221078) and UCL Research Ethics Committee (UCL Project ID: 16/0762).

\section{Provenance}

Freely submitted; externally peer reviewed.

\section{Competing interests}

Melvyn Jones is a clinician for Herts Urgent Care, for which he receives an honorarium. All other authors have declared no competing interests.

\section{Acknowledgements}

Olaoluwa Oyawoye undertook this project as a part of the University College London iBSc in primary health care, ${ }^{21}$ supervised by Melvyn Jones. The authors wish to thank Mark Griffin for providing statistical support, and Misha Ladva of the University College London Hospital Joint Research Office, as well as the Met Office and its archive information officers for procuring the meteorological data used in this study, and David Archer and Graeme Manning of Herts Urgent Care for providing the data on home visits.

\section{Discuss this article}

Contribute and read comments about this article: bjgp.org/letters 


\section{REFERENCES}

1. British Medical Association. General practice in the UK - background briefing 2017. https://www.bma.org.uk/-/media/files/pdfs/news\%20views\%20analysis/ press\%20briefings/general-practice.pdf (accessed 1 Apr 2019).

2. Maruthappu M, Sood HS, Keogh B. The NHS Five Year Forward View: transforming care. Br J Gen Pract 2014; DOI: https://doi.org/10.3399/ bjgp14X682897.

3. British Medical Association. GP leader warns that general practice is on the brink of collapse. BMA 2018; 6 Dec: https://www.bma.org.uk/news/mediacentre/press-releases/2017/june/gp-leader-warns-that-general-practice-is-onthe-brink-of-collapse laccessed 2 Apr 2019).

4. NHS Digital. GP workload survey results. (Resources. Pdf: GP workload survey results: overview. Table 13, page 32). 2007. https://digital.nhs.uk/data-andinformation/publications/statistical/gp-earnings-and-expenses-estimates/ gp-workload-survey-results laccessed 2 April 2019).

5. Hobbs R, Bankhead C, Mukhtar T, et al. Clinical workload in UK primary care: a retrospective analysis of 100 million consultations in England, 2007-14. Lancet 2016; 387(10035): 2323-2330.

6. Ayres JG. Seasonal pattern of acute bronchitis in general practice in the United Kingdom 1976-83. Thorax 1986; 41(2): 106-110.

7. Skinner MW, Yantzi NM, Rosenberg MW. Neither rain nor hail nor sleet nor snow: provider perspectives on the challenges of weather for home and community care. Soc Sci Med 2009; 68(4): 682-688.

8. Fisher E, Dorning H. Winter pressures: what's going on behind the scenes? The Health Foundation and Nuffield Trust, 2016. https://mww.nuffieldtrust.org.uk/ files/2018-10/1540144602_qualitywatch-winter-pressures.pdf laccessed 1 Apr 2019).

9. Fleming DM, Elliot AJ. The impact of influenza on the health and health care utilisation of elderly people. Vaccine 2005; 23(1): S1-S9.

10. Tammes P, Sartini C, Preston I, et al. Use of primary care data to predict those most vulnerable to cold weather: a case-crossover analysis. Br J Gen Pract 2018; DOI: https://doi.org/10.3399/bjgp18X694829.
11. Hajat S, Haines A. Associations of cold temperatures with GP consultations for respiratory and cardiovascular disease amongst the elderly in London. Int J Epidemiol 2002; 31(4): 825-830

12. Falagas ME, Theocharis G, Spanos A, et al. Effect of meteorological variables on the incidence of respiratory tract infections. Respir Med 2008; 102(5): 733-737.

13. Thornes JE, Fisher PA, Rayment-Bishop T, Smith C. Ambulance call-outs and response times in Birmingham and the impact of extreme weather and climate change. Emerg Med J 2014; 31(3): 220-228.

14. Wong HT, Lai PC. Weather inference and daily demand for emergency ambulance services. Emerg Med J 2012; 29(1): 60-64.

15. Kljakovic M, Salmond C. A model of the relationship between consultation behaviour for asthma in a general practice and the weather. Climate Research 1998; 10(2):109-113. https://www.int-res.com/abstracts/cr/v10/n2/p109-113/ laccessed 1 Apr 2019).

16. Higham J, Venables K, Kupek E, Bajekal M. Asthma and thunderstorms: description of an epidemic in general practice in Britain using data from a doctors' deputising service in the UK. J Epidemiol Community Health 1997; 51(3): 233-238

17. Hajat S, Goubet SA, Haines A. Thunderstorm-associated asthma: the effect on GP consultations. Br J Gen Pract 1997; 47(423): 639-641.

18. Togo F, Watanabe E, Park H, et al. Meteorology and the physical activity of the elderly: the Nakanojo Study. Int J Biometeorol 2005; 50(2): 83-89.

19. Porcheret $M$, Hughes $R$, Evans D, et al. Data quality of general practice electronic health records: the impact of a program of assessments, feedback, and training. J Am Med Inform Assoc 2004; 11(1): 78-86.

20. Neal RD, Hussain-Gambles M, Allgar VL, et al. Reasons for and consequences of missed appointments in general practice in the UK: questionnaire survey and prospective review of medical records. BMC Fam Pract 2005; 6: 47.

21. Jones M, Singh S, Meakin R. Undergraduate research in primary care: is it sustainable? Prim Health Care Res Dev 2008; 9(1): 85-95. 